\title{
2
}

\section{Broadening Software Engineering courses to include Organisational and Behavioural factors}

\author{
G. Beckworth, \\ School of Management Information Systems, Deakin University, \\ Geelong, Australia. \\ Phone: +61 52271393 Fax: +6152272151 \\ gbeck@deakin.edu.au
}

\begin{abstract}
This paper presents the results of qualitative research conducted by the author into the factors which affect the Requirements Engineering process. The Requirements Engineering process involves the elicitation, analysis and specification of the requirements for a proposed Information System. The results of the research reveal that the critical aspects of the process includes behavioural and organisational factors. It is proposed that many of these issues should become part of the curriculum of courses on Software Engineering and Analysis and Design.
\end{abstract}

Keywords

Requirements Engineering process, Quality Management System.

\section{INTRODUCTION}

In 1994 and 1995 I conducted research into the critical factors associated with the Requirements Engineering process. The objective was to develop a quality management system for the process and the critical success factors were used as the basis for the system. The underlying assumption was that the critical factors can be used to monitor and improve the process and if that is successful then the product quality should improve. A framework was established for the factors and the associated knowledge. Many of the factors relate to organisational and behavioural factors which gives support for the notion that Software Engineering is a socio-technical process.

This indicates that Analysis and Design courses and Software Engineering courses should be broadened to include a study of the relationships between the organisational, behavioural 
and technical factors that influence the success of the Information System development process.

\section{INVESTIGATION}

The initial research involved interviews with 30 IT practitioners from 20 different organisations including Coles Myer, Telecom, Shell, National Australia Bank, Ford, and IS consultancies. The sample is considered to be broad enough to allow some generalisations to be made. The IT practitioners were from a range of backgrounds including IS Managers, IS Analysts, Business Analysts, Managers of Business Groups and Managers of IS Planning. They were selected on the basis that they had at least 10-15 years experience and had performed a variety of roles throughout their careers.

The organisations included

IS Consultancies; Unisys, Simsion \& Bowles, Coopers \& Lybrand, Anderson Consulting, Ernst \& Young, DMR Consulting Group, SMS Consulting Group.

Retail;

Manufacturing; Coles Myer, Kmart, Target.

Petrochemical; Alcoa Australia .

Utilities;

Banking; Esso, Shell.

Barwon Water.

Telecommunications; National Australia Bank.

Postal; Telecom.

Port Authority; Car; Australia Post. Port of Geelong Authority. Ford, Mazda, RACV.

The interviews were recorded on audio tape and then transcribed to 10 to 15 pages of text for each interview. Data analysis took place immediately after the interviews and the research instrument was continually modified to adjust to the developing framework.

The data was analysed using a 'grounded theory' approach (Strauss and Corbin, 1990) and this resulted in a framework of categories and an understanding of the critical knowledge associated with the Requirements Engineering process. The grounded theory approach involves analysing the text and establishing the major concepts being discussed. In some cases this was straightforward because there would be responses to directed questions like "What do think are the critical factors involved when running workshops"?. In other cases the conversation resulted in an unsolicited response and in that situation the major concepts are noted and the framework is consulted to see which category they fit into. It was important to continually be referring back to previous text to ensure that the meanings were consistent. These categories were established from the first interview and then modified continually as the research progressed. The documents were annotated with references to the framework and as the framework was altered the annotations were updated. The framework was continually modified as the categories emerged from the analysis. To ensure that my assessment of the transcript was accurate and objective, they were analysed by another researcher and it was found that there was significant agreement between the two assessments.

The investigation into the success factors for the Requirements Engineering process has revealed important information which is grounded in current practice. This should provide a good source of knowledge from which we can supplement existing software engineering 
courses. Existing courses pay little attention to the Requirements Engineering process, the focus is more on the technical aspects of analysis, design and construction. Deming (1986) asserts that $80 \%$ of all quality problems can be attributed to failures in the process. The requirements for a quality process are poorly understood as evidenced by the continuing reports of major projects either out of control, drastically reduced in scope or abandoned.

The research identifies some of the critical knowledge requirements for successful IS implementations (Beckworth 1994). The principle outcome of the research is a set of criteria for a process quality management system. This criteria significantly expands existing standards such as ISO9004.4 for the quality of IS management.

The grounded theory analysis of the interviews resulted in the following categories as shown in the table below:

Table 1 Categories of success factors for the Requirements Engineering process

\begin{tabular}{|c|c|}
\hline Dimension & Category \\
\hline \multirow[t]{12}{*}{$\begin{array}{l}\text { I. Requirements Reflecting Business } \\
\text { Needs }\end{array}$} & $\begin{array}{l}\text { A. Establish purpose and structure of } \\
\text { the business enterprise }\end{array}$ \\
\hline & B. Defining system boundaries \\
\hline & C. Identify principal stakeholders \\
\hline & D. Clearly define goals \\
\hline & E. Facilitation \\
\hline & $\begin{array}{l}\text { F. Understand risk management } \\
\text { requirements }\end{array}$ \\
\hline & G. Management Support \\
\hline & H. Using scenarios \\
\hline & I. Ownership \\
\hline & J. Vision \\
\hline & K. User community \\
\hline & L. Prototyping \\
\hline \multirow[t]{17}{*}{ II. Quality of the Implementation Process } & A. Requirements \\
\hline & B. Experience of the analyst \\
\hline & C. Implementation strategy \\
\hline & D. Communication \\
\hline & E. Feedback capabilities \\
\hline & F. Responsiveness to clients \\
\hline & G. Understand organisational culture \\
\hline & H. Competent project group \\
\hline & I. Project management \\
\hline & J. Adequate scoping \\
\hline & K. Domain knowledge \\
\hline & L. Design \\
\hline & M. Success \\
\hline & N. Understand management politics \\
\hline & O. Time \\
\hline & P. Quality of specifications \\
\hline & Q. Champions \\
\hline
\end{tabular}




\begin{tabular}{|l|l|}
\hline & R. Reusability \\
\hline & A. Coping with change \\
\hline III. Change Management & B. Forces of change \\
\hline & C. Reasons for resistance to change \\
\hline & $\begin{array}{l}\text { D. Political issues associated with } \\
\text { change }\end{array}$ \\
\hline & E. Impact of change \\
\hline & $\begin{array}{l}\text { F. \& G. Challenges to development } \\
\text { from within and outside the organi- } \\
\text { sation }\end{array}$ \\
\hline & $\begin{array}{l}\text { H. Understand potential reasons for } \\
\text { failure }\end{array}$ \\
\hline
\end{tabular}

The categories were organised into three dimensions. "Requirements reflecting business needs" relates to the activities and issues associated specifically with the requirements engineering activities. "Quality of the implementation process" considers factors which apply across the development process and then "Change Management" contains factors which analysts need to understand in order for the process to be managed effectively.

\section{VALIDATION}

These factors were validated via an investigation conducted at Coles Myer (Beckworth 1996) and it was found that there was significant agreement with the framework. This involved interviewing nine staff from the Information Systems Planning and Development (ISPD) group and from Business groups that the ISPD group provide service to. The staff in the ISPD group included managers in strategy and planning, managers representing business groups, developers and a manager of maintenance and support. The staff from the Business groups included managers and subordinates, who have actively participated in the development process. This sample of employees were experienced enough with the process to make valued and informed judgements.

The key questions were "What are the critical factors associated with the development process?", What factors lead to the process not functioning as well as it should have"? The data from the interviews was collated and presented back to the interviewees for verification and editing. A detailed analysis of the data was conducted, initially with the manager of maintenance and support, and then, later with the manager of strategy and planning. The plan was to use the data to develop a Quality Management System which would ensure that quality losses were minimised. This would be achieved by appropriate prevention and recovery strategies. If the factors relate to the success of the process then we should be able to use them as the basis for managing the quality of the process. The appendix contains data from three of those interviews.

A conceptual model was constructed to show how the categories are interrelated (Beckworth 1996). The major components in the model were "Business needs and expectations", "Stakeholders ", "The organisational deliverable", "Process Management" and "Change and Risk Management".

The success factors and corresponding value judgement for the category "Process Management" are shown below in table 2. 
Table 2 Success factors for the Process Management category

\begin{tabular}{|l|l|}
\hline \multicolumn{1}{|c|}{ Success Factor } & \multicolumn{1}{c|}{ Value Judgement } \\
\hline Resources & $\begin{array}{l}\text { Are the resources required for the project available? Have } \\
\text { they been allocated? }\end{array}$ \\
\hline Participation & $\begin{array}{l}\text { Has the role of the participants been defined? } \\
\text { Have participants been consistently involved in the project? }\end{array}$ \\
\hline Feedback & $\begin{array}{l}\text { What is the extent and regularity of the feedback between } \\
\text { the clients and developers? }\end{array}$ \\
\hline Communication & $\begin{array}{l}\text { How regular is communication between clients and } \\
\text { developers? }\end{array}$ \\
\hline Standards & Have standards been maintained? \\
\hline Reasons for failure & $\begin{array}{l}\text { Are the people involved in the project aware of the reasons } \\
\text { why projects fail to meet their objectives? }\end{array}$ \\
\hline The process & Is the systems development process understood ? \\
\hline Issues & $\begin{array}{l}\text { Have the issues, which have been raised during the process, } \\
\text { been dealt with adequately? }\end{array}$ \\
\hline Success & What is the perceived level of success of the process? \\
\hline
\end{tabular}

\section{ANALYSIS OF RESULTS}

The research conducted at Coles Myer as well as the results from the empirical study in 1994 reveals that the critical factors for the Information Systems development process are mainly organisational and behavioural issues. How much of the courses in the MIS School at Deakin contain content which relates to the factors revealed above? If they are considered to be the critical issues as far as analysts are concerned then I think we should place more emphasis on them in our curriculum.

I that there is a place for education about these issues within business organisations. One of the immediate outcomes of this research has been a workshop program conducted at Coles Myer to try to improve the awareness of the developers to some of these issues. Several trial workshops were conducted in 1995 and the feedback from the participants was very positive. They all wanted to understand more about the nature of the development process and also to contribute to developing an improvement strategy. They felt that their understanding of the software development process could only be complete if they understood more about the organisational and behavioural factors that influenced it. Some of the issues which were raised include: client involvement in all phases, adequate feedback, communication skills, accountability, encouragement from management, right methodology to suit, users need to understand the limitations and capabilities of developers, trust between developers and clients, customer focus.

Quality analysis workshops were also conducted at the University of Central Lancashire in Preston, England in 1996 with a group of part time Masters degree students. These students were all employed within the IT industry and were mature age students. The results of these workshops show considerable support for the previous analysis. Some of the factors discussed include: clear thinking, considering all viewpoints, political sensitivity, synthesising competing requirements, understanding what people are saying, avoiding ambiguity, using appropriate language to represent the requirements, open mindedness, allowing for innovation and creativity. 
Some of the factors that were raised are problems which project managers are aware of. Why is it that these problems remain unresolved? I think that there are several reasons. The first is that the project managers learn about these factors from experience. They understand the technical aspects of the development process because they have most likely been involved in development at some stage in their careers. However they are not experienced with managing the interactions between the different groups of people involved in the process and then managing the change. Another reason is that there isn't an established framework to enable analysts to understand how to manage the quality of the process. One possibility is the Capability Maturity Model which focuses on identifying a level of expertise in software processes. I believe that the model that we are currently developing with Coles Myer could be used. One of the advantages that my approach has is that it has been developed by the employees and based on their requirements. This should improve the level of commitment to managing the quality of the process and increase the chances of continuous improvement because of a greater sense of ownership. A third reason is that these issues are particularly difficult to resolve. They are difficult because we don't understand enough about the strategies that are required to maintain acceptable levels for the success factors This is an area which I will be pursuing in future research at Coles Myer. The last reason is that the project managers and development teams are under a lot of pressure from management to meet deadlines. Some organisations measure the quality of the process in terms of being 'on time and within budget'. Management therefore needs to appreciate the value in committing resources to the management of the quality of the process.

I believe our courses need to take a more holistic view so that students can be more aware of these issues. Some of the key areas which could be integrated into existing courses include:

Communication skills:

- facilitation;

- effective communication;

- building relationships with clients.

- working with others;

- oral presentations;

- understanding groups and their effectiveness;

- feedback mechanisms.

Managing the process

- process quality;

- managing change;

- risk management;

- impact analysis

- resolving issues;

Organisational issues

- understanding organisational culture;

- developing a customer focus;

- maintaining stakeholder commitment and involvement;

Requirements Engineering

- assertion and negotiation;

- meeting expectations;

- viewpoint analysis;

- interviewing 
These topics could be developed through practical exercises so that students develop a better understanding to some of the contemporary issues facing analysts. For example running a workshop to prepare an information system plan would require planning, facilitation and evaluation. In the process of performing these exercises students would also improve their communication skills and learn more about group dynamics. References which might be used to support these topics include Warner (1996), Kerzner (1992), Rosenhead (1989), Harrington (1991).

\section{CONCLUSION}

This research indicates that the software development process is complex and to enable analysts to improve the quality of the process they need to be aware of the many and varied success factors. We need to review the curriculum to incorporate these issues into our existing courses. This would broaden the focus of existing courses and give students the opportunity to discuss and understand the issues which analysts and project managers are attempting to resolve.

\section{REFERENCES}

Beckworth, G.R., 1994, A Framework for the success factors in the Information System Development Process, Technical Report, Computing Series, School of Computing and Mathematics, Deakin University, TRC $94 / 30$.

Beckworth, G.R., 1996, A Quality Management System for the Information System development process, 3rd International Conference on Concurrent Engineering and Electronic Design Automation, Poole, UK.

Deming, W.E., 1986, Out of the Crisis, Cambridge, Mass., MIT Centre for Advanced Engineering.

Harrington, J., 1991, Organisational Structure and Information Technology, Prentice Hall.

Kerzner, H.,1992, Project Management: A Systems Approach to Planning Scheduling and Controlling, Van Nostrand Reinhold.

Paulk, M., Curtis,B., Chrissis, M., Weber, C., 1993, Capability Maturity Model for Software (version 1.1), Technical Report Software Engineering Institute, Carnegie Mellon University, CMU/SEI-93-TR-24.

Rosenhead, J., 1989, Rational Analysis for a Problematic World, Wiley.

Strauss, A., and Corbin, J., 1990, Basics of Qualitative Research: Grounded Theory Procedures and Techniques, Sage Publications Inc.

Warner, T., 1996, Communication Skills for Information Systems, Pitman Publishing London. 